\title{
CAPITAL INTELECTUAL
}

Há uma crescente e já não tão inovadora literatura na área de capital intelectual. Gestão do conhecimento, organizações que aprendem, ativos intangíveis, organizações inteligentes, capital intelectual, dentre outros, são temas que se confundem na literatura. De fato, relevadas as diferenças de ênfase, todos esses títulos se referem a uma questão central: a constatação de que o conhecimento vem se tornando o ativo/capital/recurso de maior importância estratégica para as organizações. Seguem indicações do professor Jean Jacques Salim, Coordenador-Geral dos Cursos de Especialização da FGV-EAESP e Co-Coordenador do curso Gestão do Conhecimento, no GVpec (www.fgvsp.br/conhecimento).

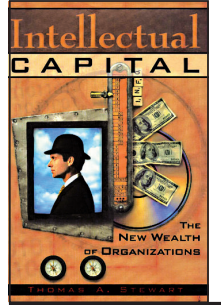

INTELLECTUAL CAPITAL: the new wealth of organizations

Thomas A. Stewart. New York : Doubleday/Currency, 1997. 278 p.

Um livro informativo, agradável de ler e escrito por um membro do conselho de editores da Fortune. Stewart teve o mérito de ser o primeiro a documentar nessa revista o interesse que o tema capital intelectual vinha despertando entre alguns executivos. Antes disso, em janeiro de 1991, publicou um breve artigo intitulado Brainpower, o qual, devido à repercussão, foi ampliado e republicado no ano seguinte.

\section{CAPITAL INTELECTUAL: descobrindo o valor real} de sua empresa pela identificação de seus valores internos Leif Edvinsson e Michael S. Malone. São Paulo : Makron, 1998. 214 p. Escrito pelo então diretor corporativo de capital intelectual da Skandia AFS, de Estocolmo, Edvinsson, e pelo editor contribuinte das revistas Forbes ASAP e Upside, Malone, esse livro destaca-se pelo fato de reproduzir a experiência e a metodologia empregada pela Skandia na gestão do capital intelectual, sendo, portanto, muito prático. O modelo é do tipo balanced scorecard, construído em torno de cinco focos: financeiro, cliente, processo, renovação \& desenvolvimento e humano.
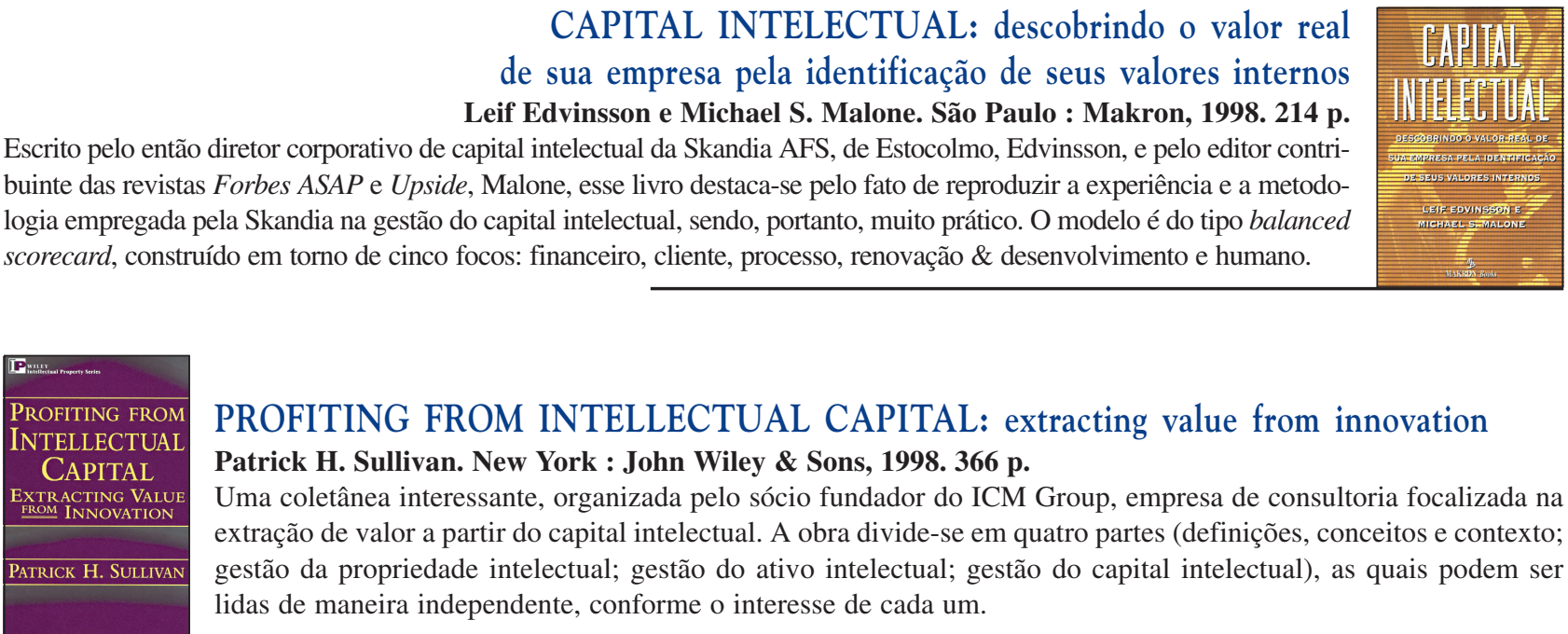

\section{PROFITING FROM INTELLECTUAL CAPITAL: extracting value from innovation} Patrick H. Sullivan. New York : John Wiley \& Sons, 1998. 366 p.

Uma coletânea interessante, organizada pelo sócio fundador do ICM Group, empresa de consultoria focalizada na extração de valor a partir do capital intelectual. A obra divide-se em quatro partes (definições, conceitos e contexto; gestão da propriedade intelectual; gestão do ativo intelectual; gestão do capital intelectual), as quais podem ser lidas de maneira independente, conforme o interesse de cada um.

WORKING KNOWLEDGE: how organizations manage what they know Thomas H. Davenport e Lawrence Prusak. Boston : Harvard Business School Press, 1998. 199 p. Escrito por Davenport - à época professor de administração na Texas University, em Austin, ex-sócio da Ernst \& Young e ex-diretor de TI na Mckinsey - e Prusak - então no IBM Consulting Group e anteriormente no Ernst \& Young's Center for Business Innovation. Os nove capítulos desse livro estão bem distribuídos entre conceituação, geração, codificação e transferência de conhecimento. Há muitos exemplos reais e um tratamento especial sobre a questão da tecnologia e do "mercado" de conhecimento.

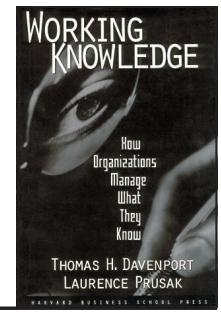

\section{THE KNOWLEDGE-CREATING COMPANY:}

how Japanese companies create the dynamics of innovation Ikujiro Nonaka e Hirotaka Takeuchi. Oxford : Oxford University Press, 1995. 284 p. Apesar do tempo decorrido (foi escrito em 1995), esse livro continua um clássico na área - consta que vendeu 40 mil cópias. Os autores fizeram um extenso e profundo trabalho de conceituação, pesquisa e apresentação de um modelo repetidamente citado na literatura. É uma obra para ser estudada e digerida, não apenas lida. Nonaka, juntamente com dois outros autores, retoma o tema em Enabling knowledge creation (Oxford, 2000, 292 p.) e merece a atenção dos que leram e gostaram da primeira obra. 


\section{GESTÃO DE MARCAS}

A preocupação com a marca é histórica. No antigo Egito, por exemplo, os fabricantes de tijolos já imprimiam símbolos em seus produtos para identificá-los. A marca é a característica mais poderosa para a formação da imagem de um produto, pois, na ausência de qualquer outro referencial, será o mais importante sinal a partir do qual o consumidor avaliará um produto. Consumidores mais exigentes e a demanda por qualidade e opções de escolha fazem da construção de novas marcas, sem dúvida, um desafio. Seguem indicações bibliográficas do professor Rubens da Costa Santos, do Departamento de Mercadologia da FGV-EAESP, compiladas por Deise Spada.

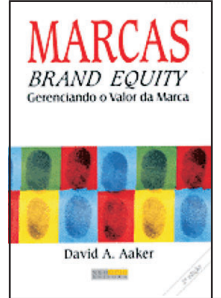

BRAND EQUITY: gerenciando o valor da marca

David A. Aaker. São Paulo : Negócio, 1998. 310 p.

É um clássico sobre o assunto que expõe, de maneira integrada, como fazer gerenciamento de marca. O autor apresenta a estrutura da relação entre a marca e seu símbolo ou slogan, abrindo cada capítulo com uma análise histórica do sucesso ou fracasso de alguma empresa na construção de sua marca - o que propicia aos gerentes uma visão mais clara de como o brand equity efetivamente proporciona valor.

\section{STRATEGIC BRAND MANAGEMENT:}

new approaches to creating and evaluating brand equity Jean-Noël Kapferer. New York : Free Press, 1992. 341 p.

Kapferer é uma autoridade internacional em gestão de marcas e marketing. Por meio de vários exemplos e estudos de casos do mundo todo, o autor retrata uma visão geral de cada aspecto da gestão de marcas, além de destacar seus perigos e armadilhas.

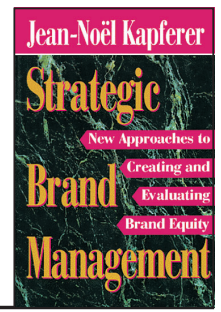

\section{Building Brands Directly}

\section{BUILDING BRANDS DIRECTLY:}

creating business value from customer relationship Stewart Pearson. Basingstoke : MacMillan Business, 1996. 432 p.

Esse livro aborda, sob a ótica do consumidor, todos os aspectos da gestão de marcas. Pearson discute como construir e garantir a sobrevivência de sua marca mediante investimentos na lealdade de seus consumidores, em um ambiente de intensa competição e mercados fragmentados.

\section{A FORÇA DA MARCA: como construir e manter marcas fortes} Mauro Calixta Tavares. São Paulo : Harbra, 1998. 220 p. Livro elaborado a partir da tese de doutoramento do autor, cujo objetivo é, passo a passo, identificar os elementos responsáveis pela construção do valor de marca e sua interação com os fatores mais importantes para o consumidor. A característica marcante da abordagem dessa obra é a operacionalização dos conceitos associados à gestão da marca.

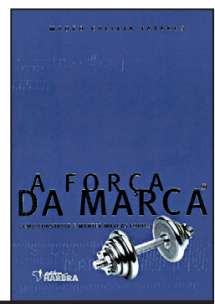

